\title{
Properties of geopolymers from conventional fly ash activated at increased temperature with sodium hydroxide containing glass powder obtained from the recycling of waste glass
}

\author{
Elżbieta Janowska-Renkas ${ }^{1, *}$, and Agnieszka Kaliciak $^{1}$ \\ ${ }^{1}$ Opole University of Technology, Civil Engineering and Architecture Faculty, Katowicka St. 48, 45- \\ 061 Opole, Poland
}

\begin{abstract}
This paper presents test results of the physical and mechanical properties of geopolymers based on conventional fly ash activated at increased temperature with sodium hydroxide, containing glass powder obtained from the recycling of waste glass.

Tests were performed on mortars of a geopolymer binder containing glass powder of various levels of fineness, at quantities ranging from 5 to $95 \%$ of the mass of the conventional fly ash. The properties of the geopolymer binder with and without the content of glass powder were determined on the basis of the heat of hydration. The suitability of the application of glass powder in geopolymers was confirmed by results of testing the following parameters using a scanning electron microscope (SEM) and analysis of micro areas (EDS) in geopolymer materials: particle size distribution, density, porosity, X-ray diffraction (XRD). Testing of the compressive strength of the geopolymer mortars was performed after: $1,7,14$ and 28 days of curing in air-dry conditions. Results of microstructure tests confirm that the glass powder coming from recycled waste glass in presence of the geopolymer binder undergoes reactions of alkaline activation at increased temperature, the products of which are zeolite minerals and sodium silicate gel. On the basis of test results of physical and mechanical properties of the geopolymers, it was proven that the content of glass powder had a beneficial effect on the utility parameters of the obtained material. The aforementioned research confirms the possibility of using waste glass for the production of geopolymer materials applied in the construction industry.
\end{abstract}

\footnotetext{
* Corresponding author: e.janowska_renkas@ interia.eu
} 


\section{Introduction}

Geopolymers are binding materials. As a result of the polycondensation reactions of aluminates and silicates they create 3D crystal lattices consisting of $\mathrm{SiO}_{4}$ and $\mathrm{AlO}_{4}$ [1-2]. The products of geopolymerisation are a N-A-S-H phase, silicon oxides, and zeolite aluminosilicates [1-3]. Aluminosilicates most often occur in volcanic rocks, as well as in the by-products of coal combustion [1-8]. One such product is fly ash, which can be used to get geopolymers [1-8]. The setting and hardening processes of geopolymers are accompanied by the dissolution of active fly ash constituents in solutions of sodium or potassium hydroxide [1, 7, 9]. The activation solution dissolves the surface of fly ash particles, filling them inside by creating a dense matrix [6]. Thus, products of the reaction are formed inside fly ash grains beyond the glassy external surface. In result of the alkaline activation reaction, smaller grains are often released as well as multi-spheres located inside the fly ash particles, which may undergo reactions with $\mathrm{OH}^{-}$groups in a later period of hardening [3]. Furthermore, the presence of reacted cenosphere grains in the form of degraded surfaces of spheres was found, which was a result of gas release from the interior of particles. Another source of silicates and aluminates is the glass powder [10-12]. Many authors indicate the pozzolanic character of the glass powder revealed in cement materials, as well as its negative impact on the life of cement materials as a result of alkali reactions (ASR-alkali silica reaction) [10-12]. In geopolymers, alkalis have a positive effect on the their hardening, the shaping of properties and curing [2]. Therefore, applications of waste glass powder to geopolymers directly involves the introduction of alkali in the form of $\mathrm{Na}_{2} \mathrm{O}_{\text {eq. }}$. Such a solution enables the utilisation of waste material in the form of glass powder, which has a negative impact on the properties of cement-based materials. Utilization of fly ash and waste glass powder for production of geopolymers is consistent with EU and national directives referring to the use of waste in line with assumptions of the circular economy and the European green deal [12-13]. Therefore, the impact of the degree of fineness and various quantities (from 5 to $95 \%$ by mass) of the waste glass powder on the shaping properties of geopolymers was tested.

\section{Test materials and methods}

Geopolymer materials were made based on conventional silica fly ash (FA) from Opole Power Plant and from waste glass powder (WGP), and their chemical composition and specific surface area according to the Blaine method are presented in Table 1.

Table 1. Chemical composition of conventional fly ash (FA) and glass powder.

\begin{tabular}{|c|c|c|}
\hline Constituent & $\begin{array}{c}\text { Conventional } \\
\text { Fly Ashes } \\
\text { (FA) }\end{array}$ & $\begin{array}{c}\text { Waste } \\
\text { Glass } \\
\text { Powder } \\
\text { (WGP) }\end{array}$ \\
\hline Loss on ignition & 1.81 & - \\
\hline $\mathrm{SiO}_{2}$ & 40.20 & 30.5 \\
\hline $\mathrm{Fe}_{2} \mathrm{O}_{3}$ & 2.00 & 0.30 \\
\hline $\mathrm{Al}_{2} \mathrm{O}_{3}$ & 6.00 & 2.52 \\
\hline $\mathrm{CaO}$ & 43.20 & 33.54 \\
\hline $\mathrm{MgO}$ & 4.70 & 0.38 \\
\hline $\mathrm{SO}_{3}$ & 0.10 & 0.08 \\
\hline $\mathrm{Na}_{2} \mathrm{O}_{\mathrm{eq}}$ & - & 2.91 \\
\hline $\mathrm{Na}_{2} \mathrm{O}$ & - & 0.32 \\
\hline
\end{tabular}




\begin{tabular}{|c|c|c|}
\hline $\mathrm{K}_{2} \mathrm{O}$ & - & 3.94 \\
\hline $\mathrm{Cl}$ & - & 0.01 \\
\hline Specific surface area & \multirow{2}{*}{3800} & 1621 \\
according to Blaine $\left[\mathrm{cm}^{2} / \mathrm{g}\right]$ & & $/ 860^{*}$ \\
\hline
\end{tabular}

*specific surface area according to Blaine for waste glass powder $A-1621 \mathrm{~cm}^{2} / \mathrm{g}$ and glass powder $B-860 \mathrm{~cm}^{2} / \mathrm{g}$, that differ in fineness (pulverisation degree)

Figure 1 shows the grain-size distribution used for the testing of conventional fly ash (FA) and waste glass powder types WGPA and WGPB determined through application of the Mastersizer 3000 laser particle size analyser. Figure 1 shows that the fly ash and applied glass powders are different in the content of fine particles within the range of 1 to $1000 \mu \mathrm{m}$. The highest fineness and content of fine particles of $<10 \mu \mathrm{m}$ were observed in the case of fly ash (FA). Out of glass powders A and B, the higher content of fine particles of $<30 \mu \mathrm{m}$ was found in the case of WGPA ground to the specific surface area equal to $1621 \mathrm{~cm}^{2} / \mathrm{g}$ compared to WGPB, which had a specific surface area two times smaller at $\mathrm{B}=860 \mathrm{~cm}^{2} / \mathrm{g}$. However, within the particle size range from 118 to $1000 \mu \mathrm{m}$, a reverse effect indicating a higher content of particles above $118 \mu \mathrm{m}$ was demonstrated by glass powder WGPB.

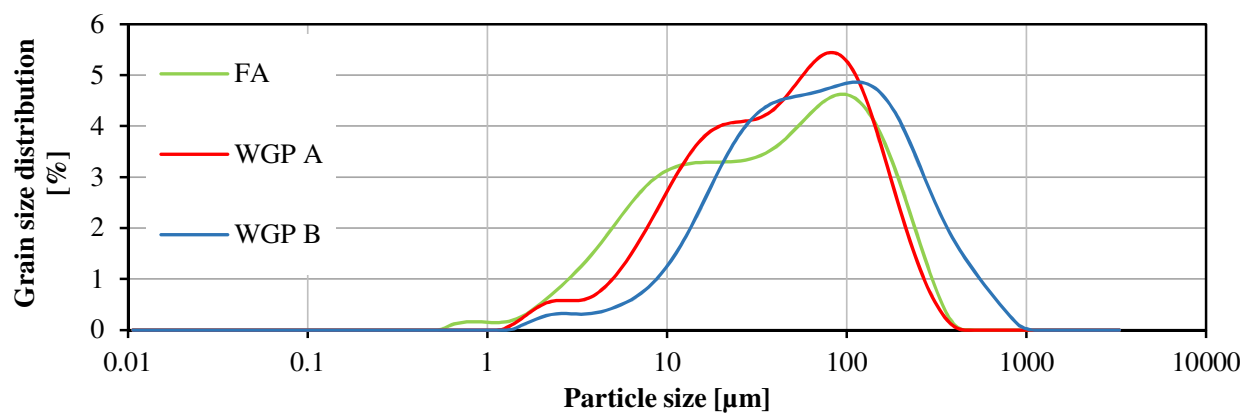

Fig. 1. Particle size distribution of conventional fly ash (FA) and waste glass powder (WGPA and WGPB).

To produce geopolymers, an 8 -molar sodium base $(\mathrm{NaOH})$ was used. Concentration of the sodium base was selected based on data provided in the literature [4]. Based on $\mathrm{Na}_{2} \mathrm{SiO}_{2} / \mathrm{NaOH}$ index, which was 2.5 , a specific quantity of sodium silicate (water glass) solution was added. Sixteen geopolymer mortar mixes were made, in which various proportions of fly ash were substituted with waste glass powder (WGP), with two different fineness values expressed by means of the specific surface area $A=1621 \mathrm{~cm}^{2} / \mathrm{g}$ and $\mathrm{B}=860 \mathrm{~cm}^{2} / \mathrm{g}$, used in quantities from 5 to $95 \%$ by mass of the content of conventional fly ash (FA). Standard sand was used in mortars, which met the requirements of the PN-EN 196-1:2016-07 standard. The composition of the geopolymer materials is presented in Table 2.

Table 2. Composition of the tested geopolymer mortars.

\begin{tabular}{|c|c|c|c|c|c|c|c|}
\hline No. & $\begin{array}{c}\text { Conventional } \\
\text { Fly Ash (FA) } \\
{[\%]}\end{array}$ & $\begin{array}{c}\text { Waste } \\
\text { Glass } \\
\text { Powder } \\
\text { (WGP) } \\
{[\%]}\end{array}$ & $\begin{array}{c}\text { Solution } \\
\text { of } \\
\mathrm{NaOH}\end{array}$ & $\begin{array}{c}\mathrm{Na}_{2} \mathrm{SiO}_{2} \\
/ \mathrm{NaOH}\end{array}$ & $\begin{array}{c}\text { Solution } \\
\text { to } \\
\text { binder } \\
\text { ratio }\end{array}$ & $\begin{array}{c}\text { Si:Al } \\
\text { (molar) }\end{array}$ & $\begin{array}{c}\text { Activation } \\
\text { process }\end{array}$ \\
\hline GP1 & 100.0 & - & \multirow{5}{*}{$8 \mathrm{M}$} & \multirow{5}{*}{2.5} & \multirow{5}{*}{0.7} & 6.7 & \multirow{5}{*}{$\begin{array}{c}\text { Water bath } \\
\mathrm{T}=85^{\circ} \mathrm{C}\end{array}$} \\
\hline GP2 & 95.0 & 5.0 & & & & 6.8 & \\
\hline GP3 & 85.0 & 15.0 & & & & 7.1 & \\
\hline GP4 & 75.0 & 25.0 & & & & 7.2 & \\
\hline GP5 & 65.0 & 35.0 & & & & 7.7 & \\
\hline
\end{tabular}




\begin{tabular}{|c|c|c|c|c|c|c|c|}
\hline GP6 & 50.0 & 50.0 & & & & 8.3 & \\
\hline GP7 & 25.0 & 75.0 & & & & 9.7 & Oven \\
\cline { 1 - 2 } GP8 & 5.0 & 95.0 & & & & 11.5 & $\mathrm{~T}=100^{\circ} \mathrm{C}$ \\
\hline
\end{tabular}

\subsection{Geopolymer synthesis}

The synthesis (setting and hardening) of geopolymer materials was conducted at two different temperatures (depending on the powder content in the geopolymers). For specimens GP2 to GP6 A and B, with waste glass powder contents of up to $50 \%$ by mass, the setting and hardening process was performed in the water bath at a temperature of $85^{\circ} \mathrm{C}$ (Table 2). For specimens GP7 and GP8 A \& B, in which the content of glass powder was increased and amounted to $75 \%$ and $95 \%$ by mass of the fly ash content, respectively, the hardening process was conducted in a lab dryer at a temperature of $100^{\circ} \mathrm{C}$. The abovedescribed diverse way of setting and hardening geopolymer materials with a high content of glass powder was selected by trial and error, as their hardening was not possible at a lower temperature $\left(85^{\circ} \mathrm{C}\right)$. After $24 \mathrm{~h}$, specimens were taken out of the moulds and stored in an airdry state at a temperature of $20 \pm 2^{\circ} \mathrm{C}$.

\subsection{Methods}

The density of hardened geopolymers was tested with a weighing method. The result of the density measurement is the average value of five separate measurements. X-ray tests of fly ash (FA) and waste glass powder (WGP), as well as geopolymer binders based on conventional fly ash with the addition of the waste glass powder, were conducted with the Philips X'PertSystem X-ray diffractometer. The measurement was performed in the $2 \theta$ angle range of $5^{\circ}$ to $60^{\circ} \mathrm{CuK} \alpha$ radiation was used. The grain size distribution was determined using Mastersizer 3000 laser particle size analyser with a wet dispersion method within the range from 0.01 to $1000 \mu \mathrm{m}$. Isopropyl alcohol was used as a dispersant. Calorimetric tests using a semi-adiabatic method were performed for the GP4A and GP4B geopolymer mortars with contents of $75 \%$ by mass of conventional fly ash and $25 \%$ by mass of waste glass powder $A$ and $B$, which had different specific surface areas $(A=1621$ $\mathrm{cm}^{2} / \mathrm{g}$ and $\mathrm{B}=860 \mathrm{~cm}^{2} / \mathrm{g}$ ). Tests were performed with the use of a calorimeter manufactured by the Controls company in line with the guidelines of PN-EN 196-9 standard 2010, the tests were conducted for $96 \mathrm{~h}$. Porosity tests were performed using a PoreMaster 60 mercury porosimeter on 28-day specimens cured in dry-air conditions. Specimens in the shape of cylinders with a diameter of $5 \mathrm{~mm}$ and a height of around $10 \mathrm{~mm}$ were cut out of geopolymer mortars. Test pieces were then dried to a constant mass at a temperature of $60^{\circ} \mathrm{C}$ and subjected to testing within a pressure range of 1 to $400 \mathrm{MPa}$. Test results were expressed by means of total porosity and volume fraction of pores of different sizes in the geopolymer matrix. Compressive strength tests of mortars made of the geopolymer binder containing the glass powder of different fineness levels used at quantities of 5 to $95 \%$ by mass of the ash-based binder were conducted in accordance with the recommendations of the PN-EN 196-1:2016-07 standard. Tests were performed on specimens with dimensions of $40 \times 40 \times 160 \mathrm{~mm}$. Specimens were taken out of the moulds after 24 hours of curing at high temperature conditions $\left(85^{\circ} \mathrm{C}\right.$ or $\left.100^{\circ} \mathrm{C}\right)$, and were then stored in an air-dry state until $1,7,14$ and 28 days had elapsed at a temperature of $20 \pm 2^{\circ} \mathrm{C}$. Microscope tests were conducted with a Quattro $\mathrm{S}$ field emission scanning electron microscope manufactured by Thermo Scientific. Imaging of the microstructure was made in low-vacuum conditions with the application of an LVD detector (image display with SE - secondary electrons). The analysis (non-model method) of EDS chemical composition was made with the application of a new generation detector by the EDAX company. 


\section{Test results}

\subsection{Density}

Figure 2 shows results of tests of the densities of geopolymer mortars with and without the addition of $A$ and $B$ glass powders of different levels of fineness $\left(A=1621 \mathrm{~cm}^{2} / \mathrm{g}\right.$ and $\mathrm{B}=860 \mathrm{~cm}^{2} / \mathrm{g}$ ) in quantities from 5 to $95 \%$ by mass. It was demonstrated that the application of the waste glass powder (WGP) to the geopolymer mortars had an effect on the density of geopolymer materials; this is illustrated in Fig. 2. The introduction of glass powder to geopolymers in amounts of up to $15 \%$ by mass leads to a gradual density increase of geopolymer materials within the range of $4 \%$ (for powder A) to $6 \%$ (for powder B). In the case of geopolymers, in which the content of glass powder was from $15 \%$ to $95 \%$ by mass, a reverse effect was observed, i.e. their density was reduced by around 11-16\%. Higher densities (from 1.8 to $3.6 \%$ ) were observed for geopolymers containing from 5 to $50 \%$ by mass of glass powder B with the lower specific surface area $\left(860 \mathrm{~cm}^{2} / \mathrm{g}\right)$. Whereas the increase of the glass powder content in geopolymers above $50 \%$ by mass caused densities higher by around $3.7 \%$ in the case of specimens containing powder A, which had a larger specific surface area $\left(1621 \mathrm{~cm}^{2} / \mathrm{g}\right)$. The density increase of geopolymer specimens with the addition of the glass powder was also observed by other authors [5].

Density of geopolymer mortars containing the waste glass powder of various fineness and amount

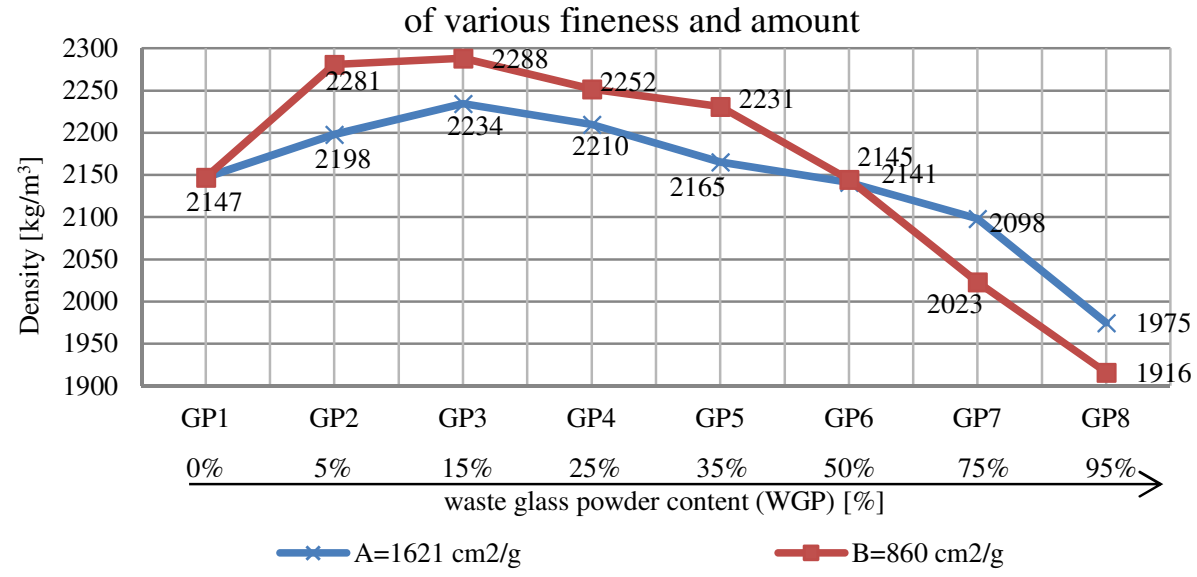

Fig. 2. Density of geopolymer mortars containing waste glass powder with the specific surface area according to Blaine of $\mathrm{A}=1621 \mathrm{~cm}^{2} / \mathrm{g}$ and $\mathrm{B}=860 \mathrm{~cm}^{2} / \mathrm{g}$ and different mass content from 0 to $95 \%$ of the binder mass.

\subsection{Heat of hardening testing}

Results of tests of the total hydration heat evolution of the geopolymer mortar without (GP1) and with glass powder A and B of different levels of fineness (GP4A and GPB, Tables 1 and 2), used at a quantity of $25 \%$ by mass are presented in Fig. 3. Table 3 shows the values of hydration heat evolution after 12, 24, 48, 72 and 96 hours. 


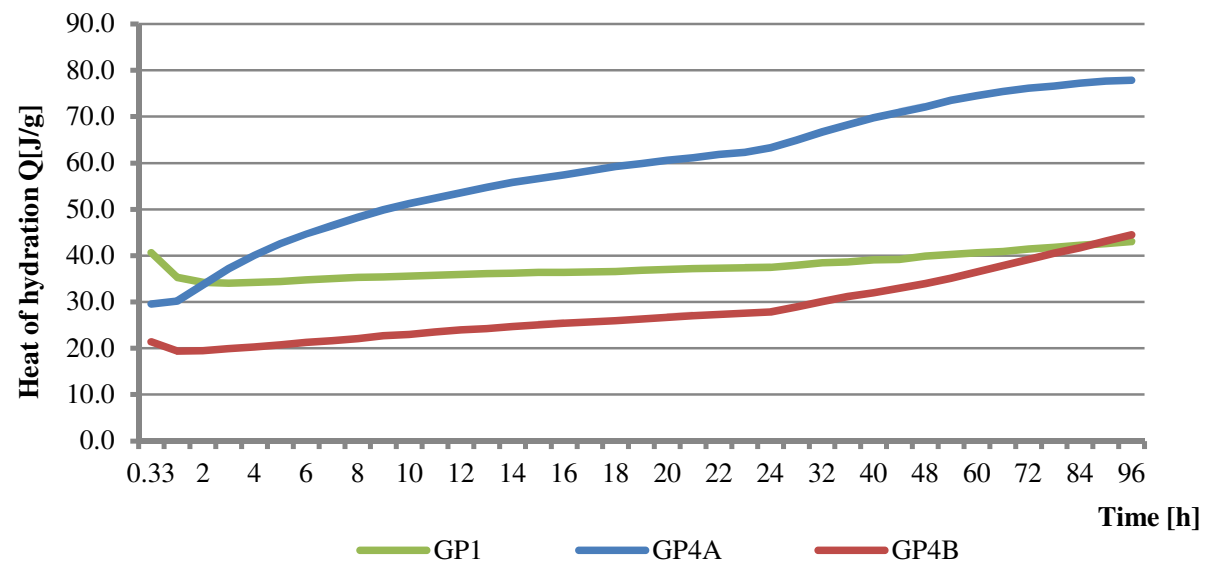

Fig. 3. Total heat evolution in geopolymer mortars with $100 \%$ content of fly ash (FA) (GP1) and mortars with $25 \%$ by mass of the waste glass powder with the different specific surface area according to the Blaine method of $\mathrm{A}=1621 \mathrm{~cm}^{2} / \mathrm{g}$ and $\mathrm{B}=860 \mathrm{~cm}^{2} / \mathrm{g}$ (GP4A and GP4B).

Table 3. Total heat evolution for conventional fly ash-based geopolymer mortars with and without $25 \%$ by mass of the waste glass powder $(\mathrm{J} / \mathrm{g})$.

\begin{tabular}{|c|c|c|c|c|c|c|}
\hline \multirow{2}{*}{$\begin{array}{c}\text { Type of } \\
\text { mortar }\end{array}$} & \multirow{2}{*}{ Composition of geopolymer } & \multicolumn{5}{|c|}{ Heat evolution value after } \\
\cline { 3 - 7 } & & $12 \mathrm{~h}$ & $24 \mathrm{~h}$ & $48 \mathrm{~h}$ & $72 \mathrm{~h}$ & $96 \mathrm{~h}$ \\
\hline GP1 & $100 \%$ FA & 36.0 & 37.5 & 39.9 & 41.4 & 43.1 \\
\hline GP4A & $75 \%$ FA + 25\% +WGPA & 53.6 & 63.3 & 72.1 & 76.2 & 77.9 \\
\hline GP4B & $75 \%$ FA + 25\% WGP B & 24.0 & 27.9 & 33.9 & 39.2 & 44.5 \\
\hline
\end{tabular}

The test results of the total hydration heat evolution demonstrated that the application of the glass powder at a quantity of $25 \%$ by mass to the geopolymer mortars had an impact on the amount of heat evolved, depending on the level of powder fineness. When powder A with higher fineness $\left(1621 \mathrm{~cm}^{2} / \mathrm{g}\right)$ and a higher content of fine particles $<3 \mu \mathrm{m}$ (Fig.1) was used in the GP4A mortar, the amount of heat evolved was almost twice as high as the geopolymer mortar without GP1 glass powder (Table 3, Fig. 3). Whereas the level of glass powder fineness that was twice as low with a specific surface area of $B=860 \mathrm{~cm}^{2} / \mathrm{g}$ and an increased content of particles larger than $118 \mu \mathrm{m}$ (in GP4B mortar), resulted in a reduction of the heat evolution by around $30 \%$ in the early hydration period of up to 24 hours compared to the GP1 mortar without the glass powder. While in the later period (from 48 to 96 hours), levels of heat evolved were comparable to the heat evolution value obtained for the geopolymer mortar without the powder (GP1). It was demonstrated that when the fineness of the glass powder A $\left(1621 \mathrm{~cm}^{2} / \mathrm{g}\right)$ was increased, the quantity of heat evolved in the GP4A mortar was around 2.5 times higher than in the GP4B mortar containing powder B with the specific surface area of $860 \mathrm{~cm}^{2} / \mathrm{g}$, which was observed in the entire period of hydration of up to 96 hours (Fig. 3, Table 3).

\subsection{Compressive strength testing of geopolymer mortars}

Figure 4 shows the results of compressive strength tests for geopolymer mortars with and without glass powder $\mathrm{A}$ and $\mathrm{B}$, used in quantities from 5 to $95 \%$ by mass, with different levels of fineness. 


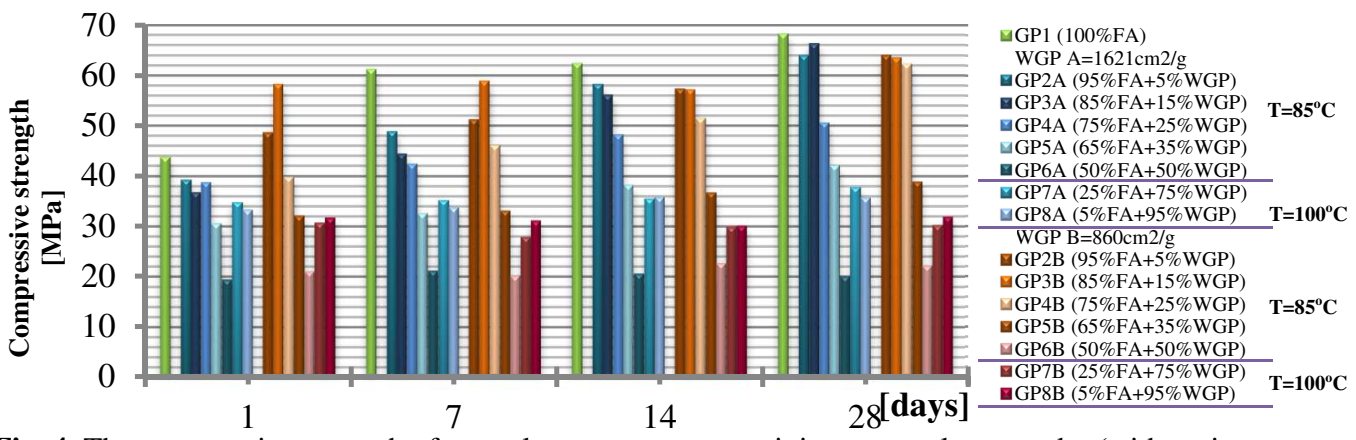

Fig. 4. The compressive strength of geopolymer mortars containing waste glass powder (with various fineness and the specific surface area equal to $A=1621 \mathrm{~cm}^{2} / \mathrm{g}$ and $\mathrm{B}=860 \mathrm{~cm}^{2} / \mathrm{g}$ according to Blaine), used in quantities from 5 to $50 \%$ by mass (activated at a temperature of $85^{\circ} \mathrm{C}$ ) and mortars containing 75 and $95 \%$ by mass of powder $\mathrm{A}$ and $\mathrm{B}$ (activated at a temperature of $100^{\circ} \mathrm{C}$ ).

Compressive strength tests (Fig. 4) demonstrated that geopolymer mortars containing glass powder B - with lower levels of fineness (specific surface area according to Blaine was 860 $\mathrm{cm}^{2} / \mathrm{g}$ ) cured at a temperature of $85^{\circ} \mathrm{C}$, within the period from day 1 to day 28 generally demonstrate higher compressive strength, as well as a higher gain of strength over time than mortars containing glass powder A with a higher level fineness $\left(A=1621 \mathrm{~cm}^{2} / \mathrm{g}\right)$. Both in the cases when glass powder A and B were applied along with the increase of the content of these powder types in the geopolymer mortar, with the simultaneous reduction of fly ash (FA) content, a gradual reduction in the compressive strength was observed in the range of 2.5 MPa (i.e. by ca. 6.4\%) in case of GP2A and GP3A mortars after 1 day of curing up to $21.9 \mathrm{MPa}$ (i.e. by ca. 52\%) in case of GP5A and GP6A mortars after 28 days of curing. Such a tendency was observed for geopolymer mortars with the content of powder A and B applied in quantities of from 5 to $50 \%$ by mass in activation conditions of $85^{\circ} \mathrm{C}$. Geopolymer mortars with the increased content of glass powder, i.e. from 75 to $95 \%$ by mass (GP7A, GP8A and GP7B, GP8B), were activated at the temperature of $100^{\circ} \mathrm{C}$, due to a long setting time at the temperature of $85^{\circ} \mathrm{C}$. Those mortars (GP7A, GP8A, GP7B, GP8B) showed the higher strength compared to GP6A and GP6B with A and B powder content in the amount of $50 \%$ by mass, activated at the temperature of $85^{\circ} \mathrm{C}$. Thus, the increase of the strength between GP7 and GP8 geopolymer mortars containing powder A at quantities of 50 and $75 \%$ by mass, respectively, and with higher levels of fineness, was around $87 \%$ after 28 days of curing. For mortars GP7 and GP8 containing 50 and $75 \%$ by mass of powder B (with a lower level of fineness), the strength increase was already lower and amounted to around $36 \%$. Furthermore, it was demonstrated that in the early curing period, up to 7 days, geopolymer mortars containing glass powder B (with a lower level of fineness) showed the higher strength. While after 14 days, the reverse effect was observed, i.e. the higher strength of mortars was found for those containing powder A, with its higher level of fineness (regardless of its content in mortars from 5 to $95 \%$ by mass). It was demonstrated that mortars containing both $\mathrm{A}$ and $\mathrm{B}$ glass powder in quantities from 5 to $15 \%$ by mass (activated at a temperature of $85^{\circ} \mathrm{C}$ ) showed the highest compressive strength, which was particularly visible after 14 days of testing. While in the same activation conditions, geopolymer mortars with a waste powder content of $50 \%$ by mass showed the lowest compressive strength values (Fig. 4).

\subsection{Testing of porosity}

Table 4 shows the results of the total porosity testing along with a change of pore volume distribution in geopolymer mortars with glass powder A and B used at a quantity of $15 \%$ by 
mass in the GP3A and GP3B mortars (which show the highest compressive strength) as well for GP6A and GP6B mortars with $50 \%$ by mass content of the glass powder (which show the lowest compressive strength) after 28 days of activation at a temperature of $85^{\circ} \mathrm{C}$. For mortars activated at a temperature of $100^{\circ} \mathrm{C}$, porosity tests were conducted on specimens GP8A and GP8B with the highest content of glass powder A and B $95 \%$ by mass.

Table 4. Total porosity and volume fraction of pores of various sizes.

\begin{tabular}{|c|c|c|c|c|c|c|c|c|}
\hline \multirow[b]{2}{*}{$\begin{array}{c}\text { Type } \\
\text { of } \\
\text { mortar }\end{array}$} & \multirow{2}{*}{$\begin{array}{c}\text { FA/WGP } \\
\text { Specific } \\
\text { surface } \\
\text { area } \\
\text { according } \\
\text { to Blaine } \\
\text { method } \\
{\left[\mathrm{cm}^{2} / \mathrm{g}\right]}\end{array}$} & \multirow[b]{2}{*}{$\begin{array}{c}\text { Apparent } \\
\text { density } \\
{\left[\mathrm{g} / \mathrm{cm}^{3}\right]}\end{array}$} & \multirow[b]{2}{*}{$\begin{array}{c}\text { Total } \\
\text { porosity } \\
{[\%]}\end{array}$} & \multicolumn{5}{|c|}{ Percentage of pores [\%] } \\
\hline & & & & $<20 \mathrm{~nm}$ & $\begin{array}{c}20-200 \\
\mathrm{~nm}\end{array}$ & $\begin{array}{c}200-2000 \\
\mathrm{~nm}\end{array}$ & $\begin{array}{c}2000- \\
20000 \\
\mathrm{~nm}\end{array}$ & $\begin{array}{c}<20000 \\
\mathrm{~nm}\end{array}$ \\
\hline GP1 & 3800 & 8.48 & 8.48 & 15.1 & 2.0 & 1.6 & 66.9 & 14.1 \\
\hline GP3A & \multirow{3}{*}{$\begin{array}{c}\text { A } \\
1621\end{array}$} & 2.39 & 8.20 & 18.2 & 5.4 & 3.9 & 53.5 & 18.4 \\
\hline GP6A & & 2.30 & 9.50 & 6.5 & 3.8 & 1.6 & 69.8 & 18.2 \\
\hline GP8A & & 3.26 & 18.24 & 2.5 & 0.8 & 2.7 & 8.9 & 85.1 \\
\hline GP3B & \multirow{3}{*}{$\begin{array}{c}\text { B } \\
860\end{array}$} & 2.34 & 9.63 & 10.3 & 3.1 & 7.0 & 58.6 & 20.6 \\
\hline GP6B & & 2.13 & 10.55 & 8.1 & 8.6 & 2.3 & 32.3 & 48.1 \\
\hline GP8B & & 3.08 & 17.62 & 2.3 & 0.7 & 2.6 & 8.5 & 85.9 \\
\hline
\end{tabular}

*Waste glass powder with specific surface area according to Blaine $A=1621 \mathrm{~cm}^{2} / \mathrm{g}$ and $B=860 \mathrm{~cm}^{2} / \mathrm{g}$

It has been demonstrated that the introduction of glass powder A or B in quantities from 15 to $50 \%$ by mass to geopolymer mortars activated at a temperature of $85^{\circ} \mathrm{C}$ led to a reduction of the total porosity along with the increase of the powder content (Table 4). With the addition of powder A, with the higher level of fineness $\left(1621 \mathrm{~cm}^{2} / \mathrm{g}\right)$, a slightly higher total porosity of geopolymer mortars was demonstrated than with the addition of powder B, with the lower level of fineness $\left(860 \mathrm{~cm}^{2} / \mathrm{g}\right)$. The above results follow the trend indicating that the strength of geopolymer mortars reduces as the content of the glass powder increases, which was confirmed by the conducted tests (Fig. 4). On the other hand, when temperature of activation was higher (i.e. $100^{\circ} \mathrm{C}$ ) for the content of both powders $\mathrm{A}$ and $\mathrm{B}$ increased to $95 \%$ by mass in the GP8A and GP8B geopolymer mortars, an increase in their porosity to around $17 \%$ was observed compared to mortars activated at the lower temperature.

Mortars GP3A and GP3B with $15 \%$ by mass of A and B powders showed an increased content of pores in the range of 2,000 to $20,000 \mathrm{~nm}(53.5 \%$ for GP3A and $58.6 \%$ for GP3B), but the content of pores was lower than in the case of the GP1 geopolymer mortar with a $100 \%$ content of conventional $(66.9 \%)$. The increased content of A and B glass powder of up to $50 \%$ by mass in mortars GP6A and GP6B indicated differences in the volume fraction of pores. Geopolymer mortar GP6A showed double the content of pores in the range of 2,000 to $20,000 \mathrm{~nm}(69.8 \%)$ than the GP6B mortar $(32.3 \%)$. As the obtained results of tests show, despite the total porosity in the geopolymer mortars decreased along with the increase of glass powder content from 5 to $50 \%$ by mass, the strength of these mortars reduced. The above can be explained by an effect of porosity reduction due to filling the pores with powder, as observed and demonstrated by Samarkon et al. [14]. These authors showed that the increase of glass powder content in geopolymers leading to a reduction of the total porosity was not as a result of a reaction causing the formation of a larger quantity of minerals but of filling in the air-voids and the presence of agglomerated particles, between which, such weak bonds were created that they did not have any impact on geopolymer strength increase. 
On the other hand, in the case of GP8 mortar activated for $24 \mathrm{~h}$ at a temperature of $100^{\circ} \mathrm{C}$, the higher content of A and B glass powder of up to $95 \%$ by mass, causes an increase of the total porosity expressed by the highest percentage (around $85 \%$ ) of large pores $>20,000 \mathrm{~nm}$. A higher porosity of these mortars (GP8A and GP8B) may be caused by the formation of sodium silicate gel, the presence of which may lead to the formation of microcracking [15], visible in the microscope images (Fig. 12-17). Redden et al. [15] explain the formation of the cracked microstructure by the high activation temperature of the geopolymers.

\subsection{X-ray diffraction (XRD)}

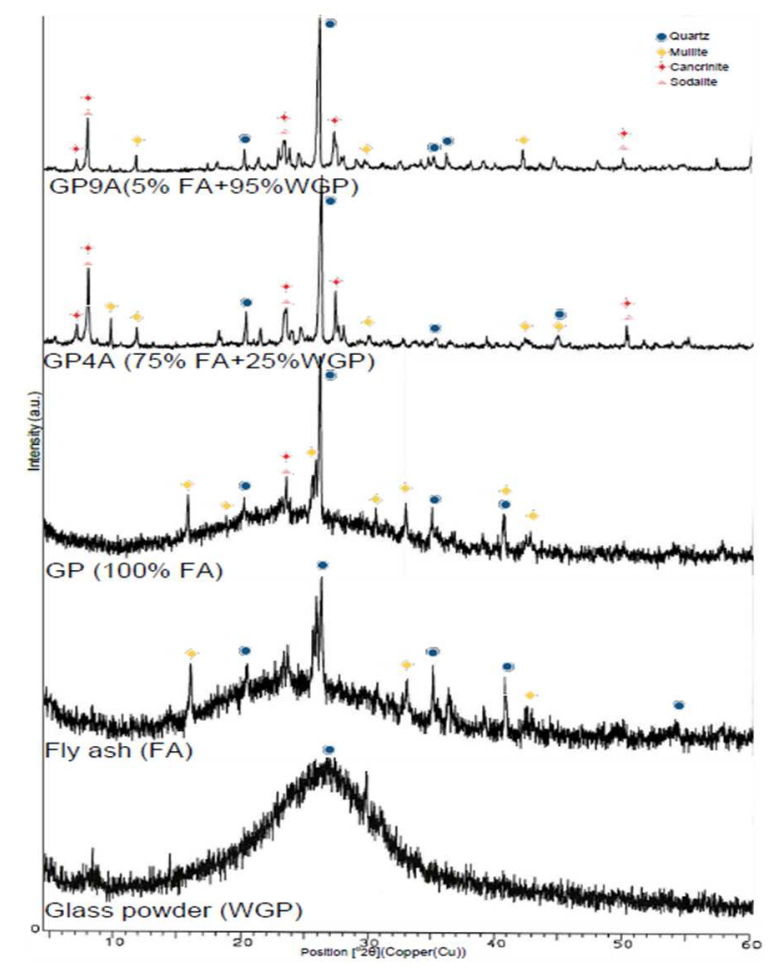

Fig. 5. An X-ray diffractogram of fly ash, glass powder, geopolymer binders GP1, GP4A, GP9A, after 28 days of curing in an air-dry state.

The results of X-ray diffraction testing show that the alkaline activation of fly ash caused the formation of zeolite minerals, mainly sodalite, which had a peak value with the highest intensity at an angle of $24.50^{\circ} 2 \theta$. As demonstrated by the authors of previous research [5] the intensity of sodalite peaks depends on the capability of a cation exchange occurring between fly ash and the activation solution. Other peaks mainly come from minerals present in silica fly ash (i.e. from quartz, mullite, and hematite), at the lower activation temperature $\left(85^{\circ} \mathrm{C}\right)$, the reaction of phase constituents did not occur. The GP1 binder has an increased background, which is a result of the content of the geopolymer amorphous phase. Geopolymers with the addition of waste glass powder have a more crystal structure, which is indicated by increased intensities of cancrinite and sodalite peaks in the diffractogram. The occurrence of sodalite phases $\left(\mathrm{Na}_{4} \mathrm{~A}_{13} \mathrm{Si}_{3} \mathrm{O}_{12} \mathrm{Cl}\right)$ and cancrinite phases $\left(\mathrm{Na}_{8}\left(\mathrm{Al}_{6} \mathrm{Si}_{6} \mathrm{O}_{24}\right)(\mathrm{OH})_{2,04}\left(\mathrm{H}_{2} \mathrm{O}\right)_{2,66}\right)$, was demonstrated as characteristic zeolite minerals, The presence of those phases in geopolymers were also confirmed by authors of papers $[4,16]$. 


\subsection{Scanning electron microscopy (SEM)}

The results of microstructure tests of conventional fly ash-based geopolymer mortars (GP1) and geopolymer mortars with the $95 \%$ by mass content of glass powder A and B (GP8A and GP8B) by means of scanning electron microscopy after 28 days of curing are presented in Figs. 5-10.

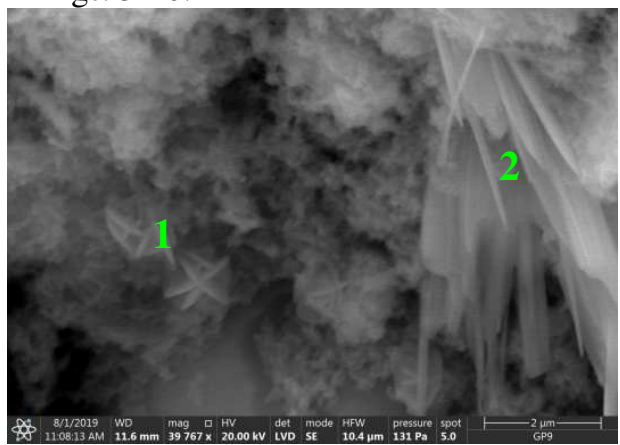

Fig. 6. Microstructure of GP1 mortar after 28 days of curing in an air-dry state; visible minerals of 1-hydroxysodalite and 2-cancrinite.

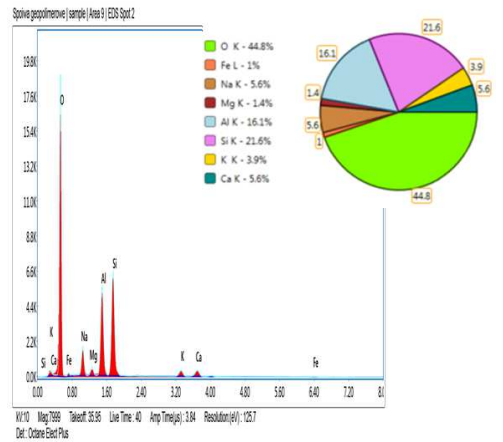

Fig. 8. Microanalysis of chemical composition (EDS) of GP1 mortar in point 1 from Fig. 6.

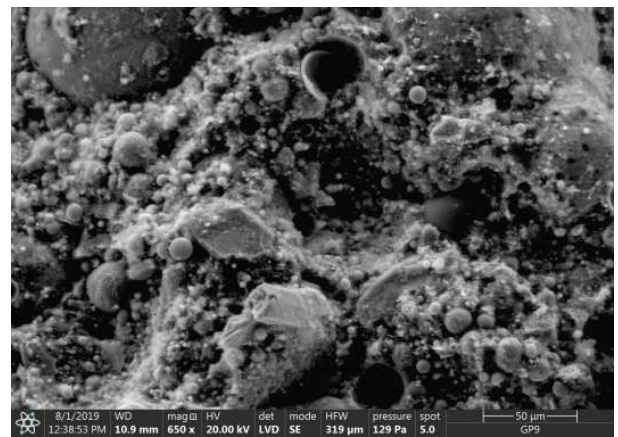

Fig. 10. Microstructure of GP4A geopolymer mortar after 28 days of curing in an air-dry state; visible diverse microstructure.

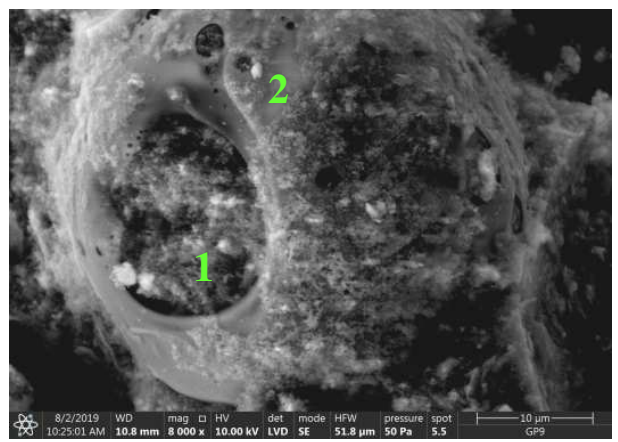

Fig. 7. Microstructure of GP1 mortar after 28 days of curing in an air-dry state; visible fly ash grain partly dissolved.

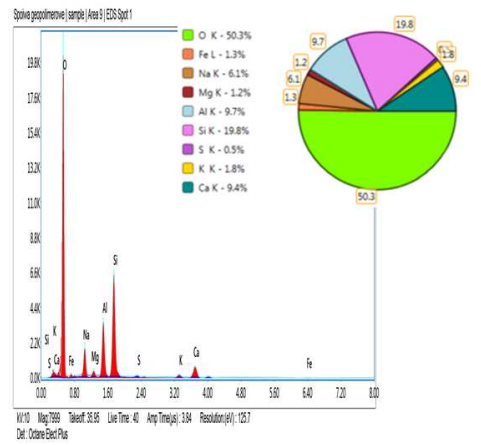

Fig. 9. Microanalysis of chemical composition (EDS) of GP1 mortar in point 2 from Fig. 6.

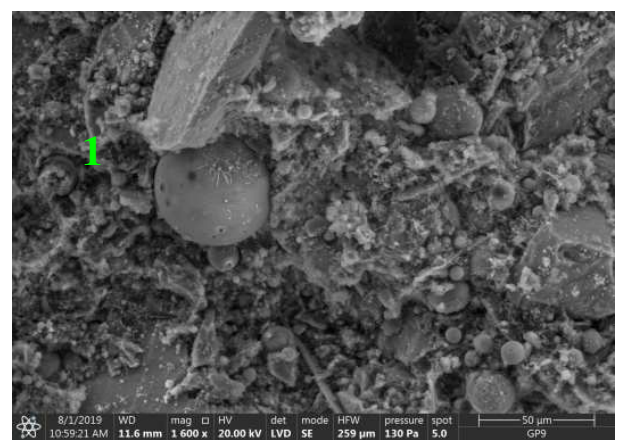

Fig. 11. Microstructure of GP4B geopolymer mortar after 28 days of curing in an air-dry state; visible diverse microstructure. 


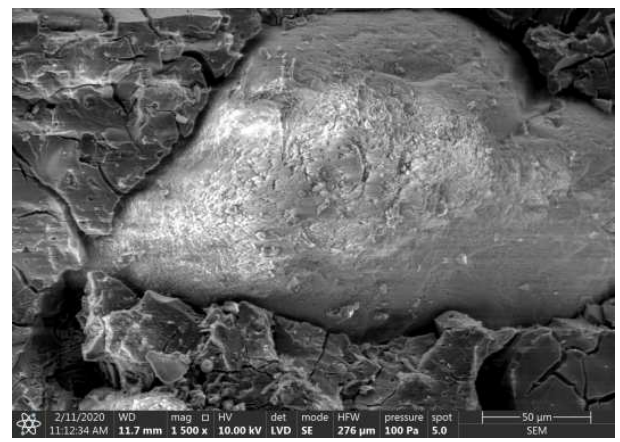

Fig. 12. Microstructure of GP6A geopolymer mortar after 28 days of curing in an air-dry state; a wall effect visible.

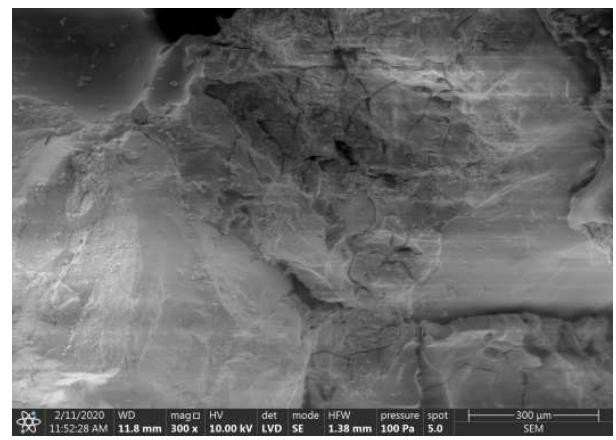

Fig. 14. Microstructure of GP8A geopolymer mortar after 28 days of curing in an air-dry state; cracked structure of the mortar visible.

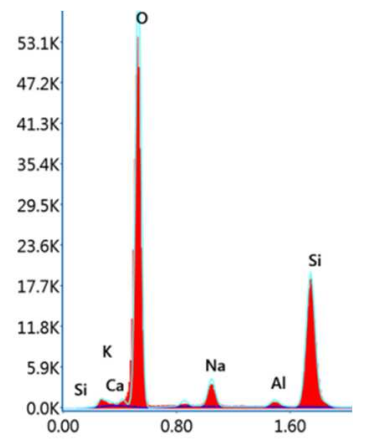

Fig. 16. Microanalysis of chemical composition (EDS) of GP8 mortar in point 1 from Fig. 12 showing chemical composition of sodium silicate gel.

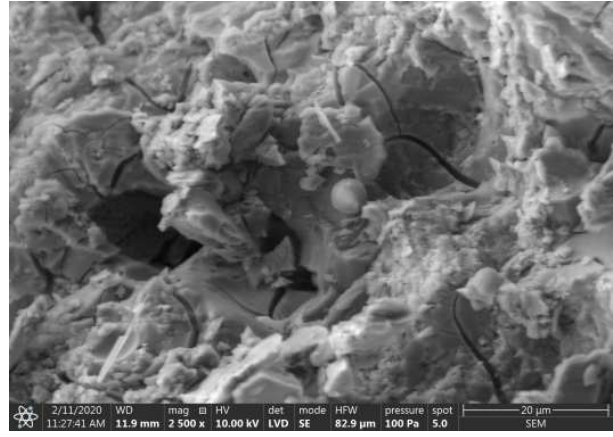

Fig. 13. Microstructure of GP6B geopolymer mortar after 28 days of curing in an air-dry state; cracked matrix visible.

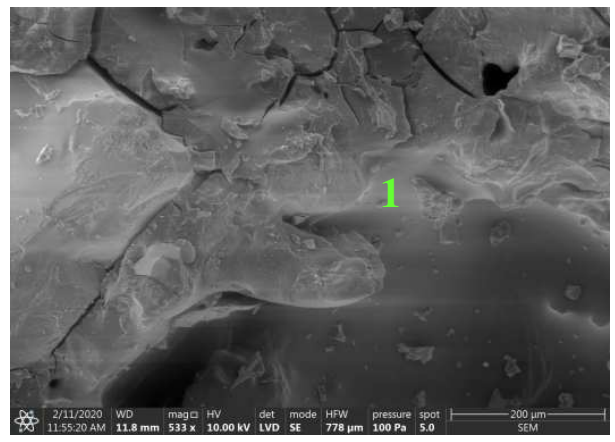

Fig.15. Microstructure of GP8B geopolymer mortar after 28 days of curing in an air-dry state; sodium silicate gel visible.

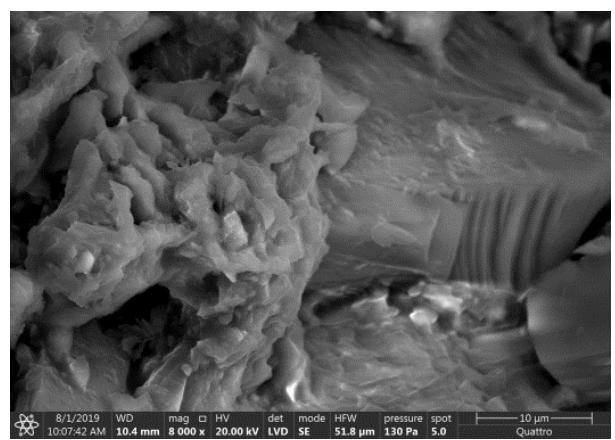

Fig. 17. Microstructure of GP8B geopolymer mortar after 28 days of curing in an air-dry state; porous structure visible.

The tests of microstructure correspond with results of X-ray diffraction with regard to the presence of the sodalite. Its presence is confirmed by Picture 5, where sodalite minerals with a characteristic spherical structure are visible. In addition, cancrinite minerals with an oblong, flat structure are identified (Fig. 6). The presence of these minerals was also found 
in GP1 geopolymer mortar, made with $100 \%$ by mass of silica fly ash (FA). According to the authors of the paper [3], the course of an alkaline activation reaction depends on the degree of dissolution of fly ashes. On the other hand, the location of an alkaline reaction depends on the local reactivity index of a fly ash grain, which is illustrated in Picture 7. It is shown that the fly ash grain got dissolved, which is marked in point 1 .

The microanalysis of chemical composition (EDS) (Fig. 8) showed that the fly ash grain in that place contained a larger quantity of aluminium oxides than in point 2 , in which the grain did not undergo dissolution reactions (Fig. 9). A product of fly ash surface dissolution may be the N-A-S-H phase, which is proven by the partly dissolved fly ash grains visible in Fig. 7. Such an opinion corresponds with the results of tests presented in previous research [3]. Picture 10 shows the visible diverse microstructure of GP4A geopolymer mortar with a glass powder (WGP) content of $25 \%$ by mass. Furthermore, there are unreacted and partly dissolved grains of silica fly ash visible, as well as residues of cenosphere surfaces. The glass powder in GP4A is moulded into this geopolymer matrix structure. The microstructure of GP4B mortar (Fig. 11) is rich in zeolite materials and products being a result of the alkaline activation reaction. Figure 11 present smaller grains, of fly ash (multispheres), being in presence of oblong cancrinite minerals.

Picture 11 also shows spherical minerals of hydroxysodalite, as well as fly ash reacted at the surface. The microstructure of GP6A mortar presented in Fig. 12 is homogeneous, but it has a very large number of microcracks, which is caused by the high agglomeration of waste glass powder particles, which is also indicated by the authors previous papers[14]. Moreover, Picture 12 shows a visible cracked and weakened zone between the sand grain and the geopolymer matrix. Such a phenomenon may be explained by the low compressive strength of GP6 mortars (Fig. 4). The microstructure of GP6B mortar presented in Fig. 15 shows a large number of microcracks, as in the case of BP6A geopolymer mortar. In this case there are single, unreacted grains of fly ash visible, which was not demonstrated in case of the GP6A mortar. The GP8A geopolymer mortar with $95 \%$ by mass of glass powder (WGPA) has a homogeneous microstructure with a large number of microcracks, which are visible in Fig. 14.

Figures 15 and 17 present the microstructure of GP8B mortar with 5\% by mass of fly ash (FA) and $95 \%$ by mass of waste glass powder WGPB, activated at the temperature of $100^{\circ} \mathrm{C}$. In Picture 15 there is an aggregate grain visible surrounded by a gel phase, as well as a glass powder grain, which forms a tight and homogeneous matrix when moulded into the geopolymer. Based on EDS analysis (Fig. 16), it can be stated that the homogeneous matrix is sodium silicate gel, which is formed as a result of the glass powder reacting with the alkaline solution [15]. Moreover, the matrix of the GP8B geopolymer shows microcracks, the presence of which is reflected by an increased total porosity as confirmed by a large content of pores $>20,000 \mathrm{~nm}$. The possible occurrence of microcracks in the structure of geopolymers with glass powder is indicated by Redden and Neithalath [15]. They explain the cracking phenomenon by too high alkalinity of the solution occurring in pores, as well as a too long activation time at the elevated temperature. Pictures 12 and 15 also show "a wall effect", where microcracks occur around the sand grain. It may prove a weakened transition zone at the border between the aggregate and the geopolymer paste. In addition, Picture 17 shows visible grains of waste glass powder surrounded by silicon rich gel. According to previous research [14], such a gel has a porous structure with various sizes of pores and cracks even reaching from 1 to $10 \mu \mathrm{m}$. 


\section{Conclusions}

Based on the obtained test results it was demonstrated that:

- The level of fineness of the glass powder has an impact on the properties of geopolymers. The application of the glass powder (A) with the higher content of fine particles results in an increased amount of hardening heat evolved and a higher density of geopolymer materials. Whereas the application of glass powder (B) with its lower level of fineness, and thus a lower content of fine particles and a smaller specific surface area, causes around a 2.5 times reduction of heat evolved during hardening of the geopolymer mortars, as well a reduction of their density compared to the mortar containing glass powder (A) with a higher content of fine particles.

- Geopolymers based on conventional fly ash (FA) with glass powder (WGP) content showed the presence of minerals in the form of zeolites and sodium-silicate gel - products that determine the properties of geopolymer materials. The increased content of sodium silicate gel was demonstrated along with the increase of glass powder content in geopolymers.

- Higher strength in the initial cure period, up to 7 days, was shown by geopolymer mortars containing from 5 to $50 \%$ by mass of glass powder B - the variant with the lower level of fineness. Whereas after 14 days, the reverse effect was observed, i.e. higher strength of geopolymer mortars was obtained for those containing up to $50 \%$ by mass of glass powder A the variant with a higher level of fineness.

- Mortars containing up to $15 \%$ by mass of both glass powder A and B (activated at a temperature of $85^{\circ} \mathrm{C}$ ) showed the highest compressive strength values, which was particularly visible after 14 days of testing. While in the same activation conditions, the least favourable strength (i.e. the lowest values) were achieved for geopolymer mortars with a waste powder content of $50 \%$ by mass.

- With an increased content of glass powder above $75 \%$ by mass, the increase of geopolymer activation temperature to $100^{\circ} \mathrm{C}$ is required in the presence of a $\mathrm{NaOH}$ solution with a high concentration $(8 \mathrm{M})$, which causes the formation of microcracks in the microstructure of geopolymers that weaken their matrix. Too high a temperature of activation may cause cracking of sodium silicate gel, which has also been proven by other authors. It has a direct impact on the demonstrated higher porosity and reduced compressive strength of geopolymers with the increased content - 75 and $95 \%$ by mass of glass powder.

- The introduction of glass powder A or B in quantities from 15 to $50 \%$ by mass, irrespective of its fineness, to geopolymer mortars activated at a temperature of $85^{\circ} \mathrm{C}$ leads to a reduction of the total porosity along with the increase of the powder content. Geopolymer mortars containing glass powder (A) with the higher level of fineness (1621 $\mathrm{cm}^{2} / \mathrm{g}$ ) showed a slightly higher total porosity compared to geopolymers with powder (B), which has the lower level of fineness $\left(860 \mathrm{~cm}^{2} / \mathrm{g}\right)$. The above follows the trend indicating that the strength of geopolymer mortars reduces as the content of the glass powder increases.

- Along with the increase of the glass powder content from 5 to $50 \%$, the reduction of the total porosity and the compressive strength of geopolymer mortars was observed. Reduction of the total porosity may be explained by filling in the air-voids by glass powder agglomerate, which forms such weak bonds so that they do not have any impact on the increase of geopolymers strength. 


\section{References}

1. M. Chau-Khun, A. Z. Awang, W. Omar, Constr. Build. Mater. 186, 90-102 (2018)

2. J. Davidovits, Geopolymer Chemistry and Applications (Geopolymer Institute, Saint Quentin, France, 2008)

3. A. Fernandez-Jimenez, A. Palomo, M. Criado, Cem. Concr. Res. 35, 1204-1209 (2005)

4. S. E. Wallah, S. V. Rangan, Low calcium fly ash based geopolymer concrete long term properties, Research Report GC2 (Curtin University of Technology, Faculty of Engineering, Perth, 2006)

5. D. D. B. Nergis, M. M. A. B. Abdullah, A. V. Sandu, P. Vizureanu, Materials 13, 343 (2020)

6. A. Derdacka-Grzymek, A. Stok, Cement Lime Gypsum 8-9, 220-222 (1980)

7. A. Fernandez-Jiménez, A. Palomo, Alkali-activated fly ashes: Properties and characteristics, 11th International Congress on the Chemistry of Cement, Durban, South Africa (2003)

8. A. Palomo, S. Alonso, A. Fernandez-Jimenez, I. Sobrados, J. Sanz, J. Am. Ceram. Soc. 87 (6), 1141-1145 (2004)

9. R.H. Abdul Rahim, T. Rahmiati, K.A. Azizli, Z. Man, M.F. Nuruddin, L. Ismail, Mater. Sci. Forum 803 (2014)

10. A. Shayan, A. Xu, Cement and Concrete Res. 36, 457-468 (2006)

11. M. Cyr, R. Pouhet, Resistance to alkali-aggregate reaction (AAR) of alkali-activated cement-based binders (Handbook of Alkali-activated Cements, Mortars and Concrete, 398-422, 2015)

12. V. Letelier, B. I., Henriquez-Jara, M. Manosalva, C. Parodi, J. M. Ortega, Energies 12, 1-18 (2019)

13. K. Afshinnia, P. R. Rangaraju, Constr. Build. Mater. 81, 257-267 (2015)

14. M. H. Samarakoon, P. G. Ranjith, V. R. S. De Silva, Constr. Build. Mater. 241, 1-16 (2020)

15. R. Redden, N. Neithalath, Cem. Concr. Compos. 45, 46-56 (2014)

16. N. Toniolo, A. Rincon, J. A. Together, P. Ercole, E.Bernando, A.R. Boccaccini, Constr. Build. Mater. 188, 1077-1084 (2018) 